\title{
AÇÃO DO BAP NA REGENERAÇÃO IN VITRO DE BLC OWEN HOLMES PONKAN X BRASSAVOLA DIGBIANA No $2^{1}$
}

\author{
BAP (6-benzylaminopurine) in the regeneration in vitro of Blc Owen \\ Holmes Ponkan x Brassavola digbiana $\mathrm{n}^{\circ} 2$
}

\author{
Luciana Giatti², Giuseppina Pace Pereira Lima ${ }^{3}$
}

\begin{abstract}
RESUMO
A Cattleya é considerada a mais bela e procurada de todas as orquídeas. Esta demanda cria a necessidade do desenvolvimento de técnicas mais eficazes de propagação que ofereçam maior número de indivíduos em período de tempo e espaço físico reduzido, além de manterem a uniformidade e a identidade genotípica para atender às exigências do mercado. Objetivou-se neste trabalho avaliar a regeneração de meristemas provenientes de gemas cultivadas in vitro do híbrido Blc Owen Holmes Ponkan x Brassavola digbiana $\mathrm{n}^{\circ}$ 2, em diferentes concentrações de BAP (6-benzilaminopurina). Gemas com 37 dias de cultivo foram inoculadas em meio de cultura líquido com reguladores vegetais, nos respectivos tratamentos: T1 - MS líquido + água de coco; T2 - MS + água de coco + 0,1 mg $\mathrm{L}^{-1} \mathrm{ANA}$ (ácido naftaleno acético) + 0,2 $\mathrm{mg} \mathrm{L}^{-1}$ BAP; T3 - MS + água de coco + 0,1 $\mathrm{mg} \mathrm{L}^{-1} \mathrm{ANA}+0,5 \mathrm{mg} \mathrm{L}^{-1} \mathrm{BAP}$; T4 - MS + água de coco $+0,1 \mathrm{mg} \mathrm{L}^{-1}$ ANA + 1,0 $\mathrm{mg} \mathrm{L}^{-1}$ BAP. Os subcultivos se realizaram aos 18, 32, 62, 93, 123, 153 e 184 dias e as avaliações foram feitas observando-se a porcentagem de sobrevivência, contaminação, oxidação e regeneração dos explantes. Observou-se que $86,7 \%$ dos explantes sobreviveram e aos 93 dias ocorreu o primeiro sinal de regeneração. BAP $\left(1,0 \mathrm{mg} \mathrm{L}^{-1}\right)$ promoveu resultados satisfatórios com a formação de 132 perfilhos aos 184 dias de cultivo, potencializando a técnica para produção em escala comercial dessa espécie.
\end{abstract}

Termos para indexação: Cattleya, micropropagação, meristema, citocinina.

\section{ABSTRACT}

Cattleya is considered the most beautiful and searched among all orchids. This fact creates the need of developing more effective propagation techniques to become available a greater number of individuals in reduced periods of time and physical space, besides maintenance of uniformity and genotipic identity to meet the needs of the market. The objective of this work was to evaluate the regeneration of the cultivated shoot meristematic in vitro of the hybrid Blc Owen Holmes Ponkan $\mathrm{x}$ Brassavola digbiana $\mathrm{n}^{\circ} 2$ in the different BAP (6-benzylaminopurine) concentrations. The explants were inoculated in the liquid medium with or without growth regulators in the following combinations: T1: MS liquid + coconut water; T2: MS + coconut water $+0.1 \mathrm{mg} \mathrm{L}^{-1} \mathrm{NAA}+0.2 \mathrm{mg} \mathrm{L}^{-1}$ BAP; T3: MS + coconut water + $0.1 \mathrm{mg} \mathrm{L}^{-1} \mathrm{NAA}+0.5 \mathrm{mg} \mathrm{L}^{-1} \mathrm{BAP}$ and T4: $\mathrm{MS}+$ coconut water $+0.1 \mathrm{mg} \mathrm{L}^{-1} \mathrm{NAA}+1.0 \mathrm{mg} \mathrm{L}^{-1} \mathrm{BAP}$. Subcultivatings and evaluations (percentage of survival, contamination, medium color, oxidation and regeneration) were made at 18 , $32,62,93,123,153$, and 184 days. At 93 days the first signs of regeneration were observed. BAP $\left(1.0 \mathrm{mg} \mathrm{L}^{-1}\right)$ enhanced good results with the formation of 132 sprouts in the 184 days, concluded that the utilization of BAP improved morphogenic response with a higher number of shoots.

Index terms: Cattleya, micropropagation, meristem, cytokinine.

(Recebido em 9 de março de 2006 e aprovado em 22 de janeiro de 2007)

\section{INTRODUÇÃO}

É preocupante reconhecer que algumas espécies de orquídeas brasileiras encontram-se praticamente extintas no seu habitat natural, pelas práticas extrativistas para comercialização e pela devastação das matas. A preocupação crescente com a preservação do meio ambiente, associado ao emprego da técnica de micropropagação in vitro, possibilita a expectativa de que as coletas predatórias das orquídeas sejam minimizadas, permitindo-se assim, a manutenção das populações naturais destas plantas (Campos, 1996).
Sem dúvida, a grande aplicação prática das técnicas de micropropagação tem se concentrado na produção comercial de plantas. A multiplicação rápida de bilhões de mudas por ano, em períodos de tempo e espaço físico reduzidos, sem interrupção sazonal, permite ao produtor introduzir rapidamente clones selecionados, em quantidade suficiente para causar impacto no mercado (Stimart, 1986).

Os laboratórios comerciais surgiram como iniciativa das próprias companhias produtoras de mudas, com o objetivo de satisfazer as necessidades internas de material de propagação livre de doenças e/ou de acelerar os métodos

\footnotetext{
${ }^{1}$ Parte da Dissertação de Mestrado em Ciências Biológicas, AC: Bioquímica e Fisiologia Vegetal, apresentada pela primeira autora à Universidade Estadual Paulista (UNESP), Botucatu, SP.

${ }^{2}$ Mestre - Departamento de Química e Bioquímica/DQB - Universidade Estadual Paulista Júlio de Mesquita Filho - Cx. P. 510 - 18618-000 - Botucatu, SP luciana giatti2000@yahoo.com.br

${ }^{3}$ Doutora, Professora - Departamento de Química e Bioquímica/DQB - Universidade Estadual Paulista Júlio de Mesquita Filho - Cx. P. 510 - $18618-000$ Botucatu, SP - gpplima@ibb.unesp.br
} 
convencionais de propagação vegetativa, principalmente de orquídeas, que apresentam desenvolvimento vegetativo lento (Campos, 1996). Freqüentemente, técnicas e sistemas de propagação desenvolvidos pela pesquisa não têm sido otimizados na propagação comercial por causa da baixa taxa de regeneração. Assim, tais técnicas são rejeitadas em função do elevado custo e baixo rendimento (Araújo, 2004).

Os meios nutritivos utilizados para cultura de células, tecidos e órgãos de plantas fornecem as substâncias essenciais para o crescimento e controlam, em grande parte, o padrão de desenvolvimento in vitro. A composição e concentração de reguladores no meio de cultura são fatores determinantes no crescimento e no padrão de desenvolvimento na maioria dos sistemas de micropropagação (Caldas et al., 1998).

Trabalhando com diversas combinações de citocininas e auxinas na regeneração de brotos de Cymbidium, Nayak et al. (2001) observaram que grande número de protocormos se formaram após 7 semanas de cultivo empregando o meio MS (Murashige \& Skoog, 1962) e 2,5 mg L-1 de BAP (6-benzilaminopurina). Park et al. (2002) utilizaram BA (benziladenina) $\left(20 \mathrm{mg} \mathrm{L}^{-1}\right)$ e ANA (ácido naftaleno acético) $\left(1,2 \mathrm{mg} \mathrm{L}^{-1}\right)$ na regeneração de hastes florais de orquídeas do gênero Phalaenopsis e 10 a 15 protocormos se formaram após 12 semanas de cultivo. Em trabalho com gemas axilares de brotações de Cattleya em meio líquido MS com 0,2 $\mathrm{mg} \mathrm{L}^{-1}$ de cinetina, $1 \mathrm{mg} \mathrm{L}^{-1} \mathrm{de}$ ANA e $50 \mathrm{~mL} \mathrm{~L}^{-1}$ de água de coco, Ventura et al. (2002) observaram que aos 142 dias de cultivo, 100\% dos explantes se mostraram totalmente oxidados.

Poucos trabalhos relatam protocolos para micropropagação de Cattleya, principalmente seus híbridos, e a dificuldade de se obter um protocolo adequado deve-se, em grande parte, à falta de conhecimento das interações fisiológicas da regeneração e do desenvolvimento in vitro. Sendo assim, objetivou-se avaliar a regeneração de meristemas provenientes de gemas cultivadas in vitro do híbrido Blc Owen Holmes Ponkan $\mathrm{x}$ Brassavola digbiana $\mathrm{n}^{\circ} 2$, em diferentes concentrações de BAP.

\section{MATERIAIS E MÉTODOS}

O material botânico utilizado foi cedido pelo Orquidário Santa Cruz, de Santa Cruz do Rio Pardo-SP, sendo a fonte de explantes, gemas procedentes de brotações laterais do híbrido Blc Owen Holmes Ponkan x Brassavola digbiana $\mathrm{n}^{\circ} 2$.

Os brotos foram extraídos de plantas com 4 anos de idade cultivadas em vasos plásticos $\mathrm{n}^{\circ} .11$, tendo como substrato pó de xaxim com cone de pinheiros, mantidas em casa de vegetação sob condições normais de temperatura $\left(25 \pm 2{ }^{\circ} \mathrm{C}\right)$, recebendo irrigação e adubação $\left(V^{2} A L A G R O^{\circledR}\right)$ uma vez por semana e pulverizadas com fungicida (DITHANE ${ }^{\circledR} ; 1 \mathrm{~g} \mathrm{~L}^{-1}$ ) uma vez por mês.

De vinte e três vasos selecionados, foram retiradas brotações, que forneceram 49 gemas (apicais e laterais). Os brotos foram removidos das plantas matrizes através de corte tangencial longitudinal com estilete, na junção do rizoma. A seguir, foram lavados abundantemente em água corrente com detergente comercial e escova macia para não danificar o tecido vegetal. Após secos, os brotos foram pesados e medidos.

As folhas externas foram retiradas a fim de visualizar as regiões das gemas. Em câmara de fluxo laminar, as fontes de explantes foram tratadas com solução de hipoclorito de sódio comercial (Q - Boa, contendo 2 a 2,5\% de cloro ativo) a 5\% por 20 minutos, seguido de três lavagens com água deionizada com intervalos de 5 minutos. Posteriormente, foram realizados cortes de $5 \mathrm{~mm}^{3}$ nas regiões contendo gemas apicais e laterais e o material vegetal foi transferido para solução desinfestante de hipoclorito de sódio comercial (Q- Boa, contendo 2 a 2,5\% de cloro ativo) a $5 \%$ por 10 minutos, seguidos de três lavagens com água deionizada estéril, com intervalos de 5 minutos. Durante todo o processo de desinfestação, os frascos que continham o material imerso na solução desinfestante foram agitados manualmente.

Após a desinfestação, as gemas permaneceram em água deionizada estéril para evitar a desidratação e oxidação. Com o auxílio de lupa os tecidos meristemáticos foram retirados das gemas, obtendo-se assim explantes (gemas) para inoculação.

De cada broto manipulado foram removidas de uma a três gemas, as quais para evitar oxidação, após sua inoculação em meio de cultura, permaneceram 37 dias em água de coco, em câmara escura, com subcultivos semanais. Para a realização do experimento foram utilizados cocos em fruta. Após lavagem em água corrente e retirada das camadas foliares externas, os cocos permaneceram em solução desinfestante (Q-Boa, contendo 2 a 2,5\% de cloro ativo) $100 \%$ por 30 minutos. Em condições de câmara de fluxo laminar, utilizando seringas, retirou-se o volume total de água contido no interior da fruta. A água retirada foi armazenada em vidros esterilizados. De cada vidro foram retirados $10 \mathrm{~mL}$ para a verificação do $\mathrm{pH}$. Os vidros foram etiquetados e permaneceram 12 horas em câmara de fluxo laminar, em temperatura ambiente. Após esse período, certificando-se do não aparecimento de contaminações, preparou-se uma mistura para obtenção do $\mathrm{pH}$ desejado (em torno de 5,2). 
Em tubos de vidro com dimensão $20 \times 150 \mathrm{~mm}$ autoclavados a $121^{\circ} \mathrm{C}$ e $1,05 \mathrm{Kg} \mathrm{cm}^{2}$ de pressão durante 20 minutos, em condições de câmara de fluxo laminar, foram colocados $10 \mathrm{~mL}$ de água de coco, oriunda da mistura descrita anteriormente. Em temperatura ambiente, os explantes foram inoculados e os tubos vedados com dupla camada de filme transparente PVC (Rolopac*). Os explantes foram subcultivados aos 5, 12, 27 e 37 dias nas mesmas condições, no escuro.

Os tratamentos com reguladores foram realizados em explantes com 37 dias de idade. Durante o processo morfogênico, os explantes foram cultivados em meio de cultura líquido constituído pelos sais de MS (Murashige Skoog, 1962), acrescido de 3\% de sacarose, ANA e BAP, além de água de coco.

Diferentes concentrações de BAP foram adicionadas ao meio de cultura, visando estimular a regeneração das brotações e formação de perfilhos nos explantes, perfazendo um total de 4 tratamentos $\left(\mathrm{T}_{1}\right.$ : MS líquido e água de coco (1,5 mL); $\mathrm{T}_{2}$. MS líquido, água de coco, 0,1 $\mathrm{mg} \mathrm{L}^{-1}$ de ANA e 0,2 $\mathrm{mg} \mathrm{L}^{-1}$ de BAP; $\mathrm{T}_{3}$ MS líquido, água de coco, 0,1 $\mathrm{mg} \mathrm{L}^{-1}$ de ANA, 0,5 $\mathrm{mg} \mathrm{L}^{-1}$ de BAP; $\mathrm{T}_{4}$ MS líquido, água de coco, $0,1 \mathrm{mg} \mathrm{L}^{-1}$ de ANA e 1,0 $\mathrm{mg} \mathrm{L}^{-1}$ de BAP), com 7 repetições, sendo cada repetição composta de um explante por tubo de ensaio.

$\mathrm{O}$ pH do meio foi ajustado para 5,7 com $\mathrm{NaOH}$. Em seguida, os meios preparados sem água de coco (com ou sem reguladores vegetais), foram colocados em recipientes etiquetados com capacidade para $1.000 \mathrm{~mL}$, vedado com tampa de borracha, envolto por fita crepe e papel alumínio. Juntamente com as formulações, tubos de ensaio foram autoclavados a $121^{\circ} \mathrm{C}$ a $1,05 \mathrm{Kg} \mathrm{cm}^{-2}$ de pressão por 20 minutos.

Em temperatura ambiente, em condições de câmara de fluxo laminar, verificou-se o $\mathrm{pH}$ dos meios/tratamentos $\left(\mathrm{T}_{1}, \mathrm{~T}_{2}, \mathrm{~T}_{3}\right.$ e $\left.\mathrm{T}_{4}\right)$, após autoclavagem. Posteriormente, cada tubo recebeu $10 \mathrm{~mL}$ de meio de cultura e em seguida $1,5 \mathrm{~mL}$ de solução de água de coco com pH 5,20 (retiradas da fruta, sem autoclavagem). Esse procedimento se repetiu para os meios de cultura correspondentes aos tratamentos $\mathrm{T}_{1}, \mathrm{~T}_{2}, \mathrm{~T}_{3}$ e $\mathrm{T}_{4}$. Após o preparo das misturas, o $\mathrm{pH}$ foi ajustado para 5,7 .

Os explantes foram inoculados nos tratamentos e permaneceram em sala de crescimento com temperatura de $25 \pm 2{ }^{\circ} \mathrm{C}$ e irradiância de $32 \mathrm{~mol} \mathrm{~m}^{-2} \mathrm{~s}^{-1}$, fornecida por lâmpadas fluorescentes brancas de $20 \mathrm{~W}$, marca Osram $\%$ luz do dia especial e fotoperíodo de 16 horas de luz, permanecendo nessas condições durante 194 dias, com subcultivos aos 18, 32, 62, 93, 123, 153, 184 dias.
As avaliações foram feitas na mesma época dos subcultivos, sendo avaliadas as seguintes características: sobrevivência, contaminação visualmente detectável por fungos e bactérias, grau de oxidação dos explantes (verde com extremidade oxidada e base oxidada com ápice verde), coloração do meio (límpido, levemente amarelo e totalmente amarelo), regeneração e formação de perfilhos, além da área (medida em papel milimetrado) e peso final dos explantes. Contaminação, oxidação e coloração foram avaliadas visualmente. Os experimentos foram organizados de modo casualizado, em blocos ao acaso. Os dados foram submetidos à analise de variância e as médias dos tratamentos comparadas estatisticamente pelo teste de Tukey, ao nível de 5\% de probabilidade, através do "software" estatístico SISVAR (Ferreira, 2000).

\section{RESULTADOS E DISCUSSÕES}

$\mathrm{Na}$ primeira avaliação realizada aos 18 dias de cultivo observou-se a morte de $13,3 \%$ dos explantes. No tratamento, 1, 3,3\% dos explantes morreram, no tratamento 2 encontrou-se $10 \%$ de morte dos explantes. Nos demais tratamentos não ocorreu morte dos explantes.

De acordo com Arditti \& Ernst (1993), gemas axilares originadas da base de brotações novas de Cattleya em fase de multiplicação, quando cultivadas em meio líquido proporcionam maior taxa de sobrevivência, maior crescimento dos explantes e maior desenvolvimento de calo em período de tempo mais curto. No presente trabalho, verificou-se que no meio contendo maiores concentrações de BAP, os explantes apresentaram maior taxa de sobrevivência.

Durante toda a fase experimental, não foi observada contaminação por fungos ou bactérias, o que pode ter contribuído para os resultados encontrados, isto é, boa taxa de sobrevivência dos explantes. Esses resultados podem ser atribuídos à alta eficiência do método de assepsia utilizado.

A avaliação visual em relação à oxidação registrou aos 18 dias de cultivo um leve escurecimento dos explantes. A grande maioria apresentou ápices totalmente verdes (Quadro 1), exceto aqueles cultivados nos tratamentos $1 \mathrm{e}$ 2, que apresentaram escurecimento leve até o final do experimento.

Como pode ser notada, a oxidação na base ou no ápice do explante, ocorreu em todos os tratamentos, porém o grau de escurecimento não promoveu danos severos que comprometesse a condução do experimento. Resultados satisfatórios foram constatados por causa da ausência de explantes totalmente oxidados. 
QUADRO 1 - Grau de oxidação dos explantes obtidos de brotações do híbrido Blc. Owen Holmes 'Ponkan' x Brassavola digbiana $\mathrm{n}^{\circ}$ 2, em meio contendo ANA e diferentes concentrações de BAP, aos 18, 32, 62, 123, 153 e 184 dias de cultivo (VEO - verde com extremidade oxidada; BOAV - base oxidada com ápice verde).

\begin{tabular}{|c|c|c|c|c|c|c|}
\hline Período (dias) & Grau de & & ll de & oxid & & \\
\hline & & $\mathrm{T} 1$ & $\mathrm{~T} 2$ & T3 & $\mathrm{T} 4$ & \\
\hline 18 e 32 & VEO & 2 & 2 & 2 & 3 & $9^{c}$ \\
\hline & BOAV & 4 & 3 & 5 & 5 & $17^{\mathrm{b}}$ \\
\hline 62 e 93 & VEO & 2 & 2 & - & - & $4^{\mathrm{d}}$ \\
\hline & BOAV & 4 & 3 & 7 & 8 & $22^{\mathrm{a}}$ \\
\hline $123,153,184$ & VEO & 2 & 2 & - & - & $4^{\mathrm{d}}$ \\
\hline & BOAV & 4 & 3 & 7 & 8 & $22^{\mathrm{a}}$ \\
\hline $\begin{array}{l}\text { Total de oxidados } \\
\operatorname{Cv}(\%)=5,92 \%\end{array}$ & & $18^{\mathrm{bc}}$ & $15^{\mathrm{c}}$ & $21^{\mathrm{ab}}$ & $24^{\mathrm{a}}$ & \\
\hline
\end{tabular}

Médias seguidas de letras distintas diferem pelo teste de Tukey, com $\mathrm{p}<0,05$.

A oxidação causa efeitos adversos na propagação vegetativa e pode provocar limitações nas respostas morfogênicas em culturas de tecidos (Jordan et al., 1998). Esse processo é dependente da espécie e nenhum método é totalmente eficaz para todas as espécies cultivadas. No caso de Cattleya, onde o problema é acentuado, adotouse uma combinação de tratamentos com o intuito de evitála, tais como manutenção de culturas no escuro na fase de estabelecimento, subcultivos freqüentes, como recomendado por Bajaj (1995) e o uso da água de coco in natura.

Aos 62 dias de cultivo observou-se alteração de coloração dos explantes cultivados nos tratamentos 3 e 4 , que se mostraram verdes com extremidade oxidada e foram se tornando mais claros, ocorrendo dessa forma, diminuição da oxidação.

Aos 184 dias de cultivo, 15,4\% dos explantes se mostraram verdes com extremidades oxidadas e $84,6 \%$ se mostraram com base oxidada e ápice verde.

Nesse trabalho, observou-se liberação de compostos que promoveram o escurecimento do meio, provalmente fenólicos, o que comprometeu o desenvolvimento dos explantes, diminuindo a taxa de regeneração. Quando não houve oxidação, obteve-se alta taxa de regeneração. Por outro lado, explantes que apresentaram escurecimento, mostraram menor índice de regeneração. Resultados semelhantes são descritos por Maarten et al. (1997), os quais em trabalho de micropropagação com Tulipa gesneriana sugerem que a causa da baixa taxa de regeneração de explantes é, principalmente, o estresse oxidativo. Enzimas como superóxido dismutase, peroxidases, catalases e polifenoloxidases podem causar danos nas membranas, alterando o metabolismo normal, promovendo dessa forma, redução nos índices de explantes que apresentam potencial de regeneração. Myint et al. (2001) trabalhando com cultivo in vitro de folhas de Phalaenopsis (Orchidaceae), observaram que o escurecimento dos explantes não inibiu o crescimento dos PLBs (protocormóides ou perfilhos).

Ventura et al. (2002) trabalhando com gemas axilares de brotações de Cattleya em meio líquido MS com 0,2 mg $\mathrm{L}^{-1}$ de cinetina, $1 \mathrm{mg} \mathrm{L}^{-1}$ de ANA e $50 \mathrm{~mL} \mathrm{~L}^{-1}$ de água de coco, observaram que aos 142 dias de cultivo, $100 \%$ dos explantes se mostraram totalmente oxidados. Resultados diferentes foram encontrados nesse experimento, onde o meio utilizado não promoveu a oxidação total e morte dos explantes

Pal \& Raychaudhuri (2001) trabalhando com Plantago ovata constataram que concentrações elevadas de caseína hidrolisada e água de coco induziram à síntese de polifenóis gerando escurecimento dos calos e morte dos embriões.

O uso de componentes orgânicos como água de coco é benéfica nas culturas de tecidos, mas atenção especial deve ser dada à maneira com que se empregam essas substâncias, pois apresentam constituição química indefinida e geram alterações no meio de cultura, como oscilações de $\mathrm{pH}$.

A maioria das culturas se desenvolvem em $\mathrm{pHs}$ levemente ácidos, como as Cattleyas, que toleram uma faixa estreita de 5,2 a 5,4, o que diminui o grau de oxidação, garantindo o estabelecimento e a taxa de multiplicação dos 
explantes. Provavelmente, o uso de $\mathrm{pHs}$ mais ácidos poderia inibir a atividade das enzimas oxidativas, tais como a polifenoloxidase, que apresenta atividade máxima em $\mathrm{pHs}$ em torno de 6,5; com a redução do $\mathrm{pH}$, ocorre geralmente diminuição na atividade dessas enzimas (Billaud et al., 2004).

$\mathrm{O}$ meio de cultura líquido utilizado com $\mathrm{pH}$ inicial de 5,6, após a autoclavagem sofreu acidificação e atingiu o valor de 4,6. Resultados semelhantes foram observados por Piza et al. (2003), quando observaram que meios submetidos a altas temperaturas e pressão (autoclave), geralmente sofrem redução de $\mathrm{pH}$, provavelmente por ocorrer modificação das estruturas químicas presentes no meio de cultura.

A água de coco dependendo de seu estado fisiológico apresenta $\mathrm{pHs}$ diferentes, podendo oscilar entre 4,6 e 5,8. A água de coco in natura utilizada nesse trabalho, apresentou um $\mathrm{pH}$ médio de 5,2 e pode ter exercido um efeito tampão no meio de cultura, controlando o $\mathrm{pH}$ e alterando a atividade das enzimas oxidativas, como a polifenoloxidase. Além disso, sabendo que a água de coco apresenta em sua constituição química, acido málico e acido cítrico e que estes ácidos agem como agentes redutores e antioxidantes (Arditti \& Ernst, 1993), sugere-se que a ação desses compostos pode ter influenciado na obtenção dos resultados encontrados nesse trabalho, isto é, explantes com graus de oxidação leve.

Durante os subcultivos, os meios de cultura líquido apresentaram leve alcalinização (verificado através da medida do $\mathrm{pH}$ ), mostrando variação de 5,2 para 5,5, em média, sendo possível que as trocas se realizassem mensalmente, pois a coloração do meio se manteve límpida durante essa fase, tendo como conseqüência um leve escurecimento dos explantes, o qual não interferiu na condução do experimento, nem no desenvolvimento dos mesmos.
Aos 93 dias de cultivo observaram-se os primeiros sinais de regeneração, com aparecimento de alguns perfilhos. Pelos resultados apresentados no Quadro 2, evidenciam-se os explantes dos tratamentos 3 e 4 foram os primeiros a apresentar regeneração.

Ao analisar os resultados, observa-se que o tratamento $\mathrm{T} 1$, mesmo sem reguladores vegetais, apresentou brotações. Concentrações maiores de BAP promoveram maior perfilhamento, como encontrado no T3, onde foi constatada formação de 70 perfilhos e no T4, 132 perfilhos aos 184 dias, sugerindo que maiores concentrações de BAP são eficientes em estimular brotação em Blc. Owen Holmes 'Ponkan' x Brassavola digbiana $n^{\circ} 2$ (Figura 1).

Diferentes efeitos de reguladores de crescimento podem ocorrer para diferentes espécies, inclusive variações entre as cultivares dentro de uma mesma espécie. Nesse trabalho, 23\% dos explantes apresentaram sinais de perfilhamento aos 93 dias de cultivo, enquanto que aos 153 dias de cultivo, 14 explantes haviam regenerado 162 perfilhos, totalizando 254 no final do experimento. Diversos trabalhos, encontrados na literatura, relatam a eficiência dos reguladores na indução de brotações em espécies vegetais cultivadas in vitro.

Pindel \& Miczynskik (1996) utilizaram para micropropagação de orquídeas do gênero Cymbidium, 5,0 $\mathrm{mg} \mathrm{L}^{-1}$ BAP e $0,9 \mathrm{mg} \mathrm{L}^{-1}$ de ANA e obtiveram, após 2 meses de cultivo a formação de perfilhos em $86 \%$ dos explantes. Carvalho (2002) observou que a partir de gemas axilares e apicais de plantas adultas do híbrido Brassolaeliocattleya 'La Tuilerie' x Laeliocattleya Lina Cavalieri, tratadas com $1 \mathrm{mg} \mathrm{L}^{-1}$ de ANA e $0,2 \mathrm{mg} \mathrm{L}^{-1} \mathrm{de}$ cinetina, $16 \%$ dos explantes, aos 50 dias de cultivo, apresentaram resposta morfogênica.

QUADRO 2 - Número de perfilhos formados em explantes do híbrido Blc. Owen Holmes 'Ponkan' x Brassavola digbiana $\mathrm{n}^{\mathbf{o}}$ 2, em meio contendo ANA e diferentes concentrações de BAP, aos 18, 32, 62, 123, 153 e 184 dias de cultivo.

\begin{tabular}{|lccccc|}
\hline $\begin{array}{l}\text { Regeneração } \\
\text { Dias }\end{array}$ & \multicolumn{2}{c}{ Número de perfilhos } & \multicolumn{2}{c|}{$\begin{array}{c}\mathbf{N}^{0} \text { total de } \\
\text { perfilhos }\end{array}$} \\
\hline & T1 & T2 & T3 & T4 & 15 \\
93 & - & - & 5 & 10 & 48 \\
123 & 5 & 3 & 11 & 29 & 162 \\
153 & 11 & 6 & 54 & 91 & 254 \\
184 & 33 & 19 & 70 & 132 & \\
\hline
\end{tabular}



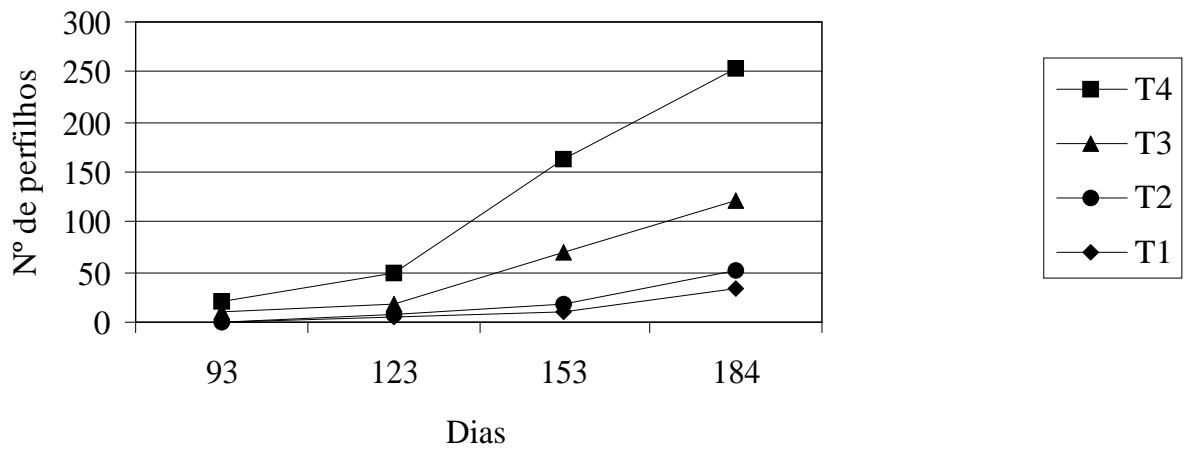

$$
\begin{array}{lll}
\text { Tratamentos } & \text { Modelo ajustado } & * \mathrm{R}^{2} \\
\text { Testemunha } & \mathrm{y}=45,988-0,908 \mathrm{x}+0,005 \mathrm{x}^{2} & 0,984 \\
0,2 \mathrm{mg} \mathrm{L}^{-1} \mathrm{BAP} & \mathrm{y}=27,706-0,541 \mathrm{x}+0,003 \mathrm{x}^{2} & 0,978 \\
0,5 \mathrm{mg} \mathrm{L}^{-1} \mathrm{BAP} & \mathrm{y}=-30,044-0,117 \mathrm{x}+0,002 \mathrm{x}^{2} & 0,931 \\
1,0 \mathrm{mg} \mathrm{L}^{-1} \mathrm{BAP} & \mathrm{y}=-30,715-0,109 \mathrm{x}+0,005 \mathrm{x}^{2} & 0,977 \\
\multicolumn{2}{c}{} & \\
\multicolumn{2}{c}{\mathrm{p}<0,05: \text { para todos os modelos ajustados }} & \\
{ }^{1} \mathrm{Y}=\mathrm{a}+\mathrm{b}_{1} \mathrm{x}+\mathrm{b}_{2} \mathrm{x}^{2} &
\end{array}
$$$$
* \mathrm{R}^{2}
$$$$
0,984
$$$$
0,978
$$$$
0,977
$$

FIGURA 1 - Número de perfilhos formados em explantes de Blc. Owen Holmes 'Ponkan' x Brassavola digbiana $\mathrm{n}^{\circ} 2$, nos diferentes tratamentos, aos 93, 123, 153 e 184 dias de cultivo.

O peso e a área média dos explantes também foram avaliados ao longo do experimento com o intuito de verificar as possibilidades de sobrevivência e a capacidade de crescimento. A área média após a retirada do tecido meristemático foi de $8 \mathrm{~mm}^{2}$, aos 37 dias atingiu $9,4 \mathrm{~mm}^{2}$, chegando a $65,4 \mathrm{~mm}^{2}$ ao final do experimento (221 dias). Em relação ao peso, aos 37 dias apresentaram 34,2 mg e no final do experimento atingiram $164,1 \mathrm{mg}$. O aumento da área dos explantes nesse experimento deve-se provavelmente, aos baixos graus de oxidação e a ação efetiva do BAP na regeneração de meristemas de Cattleya.

A partir dos resultados encontrados nesse trabalho, podemos sugerir que o uso de BAP na concentração de 1,0 $\mathrm{mg} \mathrm{L}^{-1}$ é eficiente na formação de brotações, a partir de gemas de Blc. Owen Holmes 'Ponkan' x Brassavola digbiana $\mathrm{n}^{\circ} 2$.

Geralmente, utiliza-se meio líquido para cultivos iniciais e de manutenção, acrescidos de ANA e BAP e meio sólido sem reguladores para crescimento e enraizamento. No presente experimento, utilizando ápices caulinares e gemas axilares cultivadas em água de coco e em meio liquido constituído de sais minerais MS, com 0,1 $\mathrm{mg} \mathrm{L}^{-1}$ de ANA e 1,0 $\mathrm{mg} \mathrm{L}^{-1}$ de BAP, ocorreu bom desenvolvimento morfogênico dos explantes, potencializando o método para a produção em escala comercial dessa espécie (Figura 2).

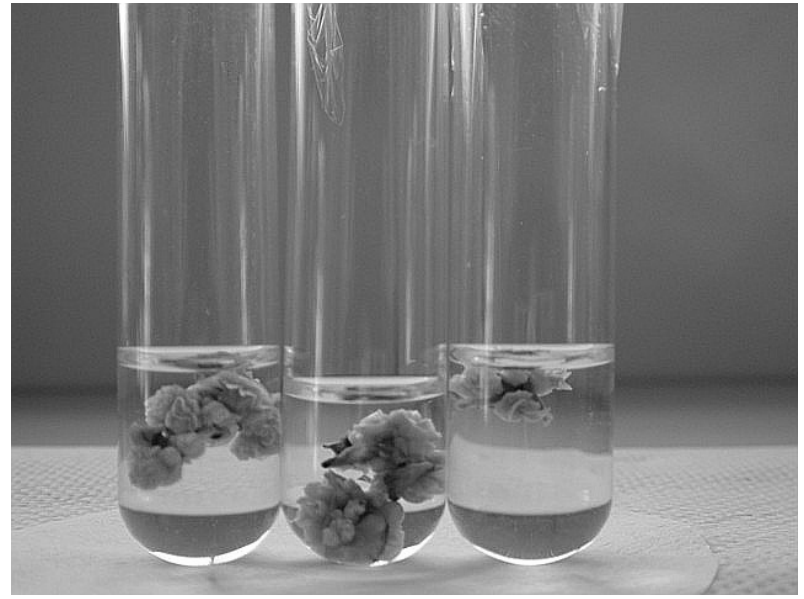

FIGURA 2 - Regeneração de explantes de Blc Owen Holmes 'Ponkan' x Brassavola digbiana $\mathrm{n}^{\circ}$ 2, após 224 dias em meio contendo $0,1 \mathrm{mg} \mathrm{L}^{-1}$ de ANA e $1,0 \mathrm{mg} \mathrm{L}^{-1} \mathrm{de}$ BAP.

\section{CONCLUSÃO}

$\mathrm{O}$ uso de meio líquido, contendo água de coco $(1,5$ $\mathrm{mL}), 0,1 \mathrm{mg} \mathrm{L}^{-1}$ de ANA e 1,0 $\mathrm{mg} \mathrm{L}^{-1}$ de BAP, para cultivo e manutenção de Blc. Owen Holmes 'Ponkan' x Brassavola 
digbiana $n^{\circ} 2$ micropropagadas é eficiente para o desenvolvimento e perfilhamento de gemas laterais.

\section{AGRADECIMENTOS} recebidos.

À FUNDUNESP, FAPESP e CNPq, pelos auxílios

\section{REFERÊNCIAS BIBLIOGRÁFICAS}

ARAÚJO, A.G. Crescimento in vitro e aclimatação de plântulas de orquídeas. 2004. 73p. Dissertação (Mestrado em Fitotecnia), Universidade Federal de Lavras, Lavras.

ARDITTI, J.; ERNST, R. Micropropagation of orchids. New York: John Wiley, 1993. 632p.

BAJAJ, Y.P.S. Automated micropropagation for an masse production of plants. In: RASAI, S.;

GEORGE, A.P.; KANTHARAJAH, A.S. Tissue culture of Annona sp. (Cherimoya, atemoya sugar apple and soursop). Berlim: Springer, 1995. p.1-14. (A Review Scientia Horticulturae, 62).

BILLAUD, C.; MARASCHIN, C.; NICOLAS, J. Inhibition of polyphenoloxidase from apple by Maillard reaction products prepared from glucose or fructose with L-cysteine under various conditions of $\mathrm{pH}$ and temperature. Food Science and Technology / Lebensmittel - Wissenschaft and Technologie, v. 37, p. 69-78, 2004.

CALDAS, L.S.; HARIDASAN, P.; FERREIRA, M.E. Meios nutritivos. In: TORRES, A.C.; CALDAS, L.S.; BUSO, J.A. (Ed.). Cultura de tecidos e transformação genética de plantas. Brasília: EMBRAPA/CNPH, 1998. v. 1, p.87-132.

CAMPOS, D. M. Orquídea: manual prático de cultura. Correa: São Paulo, 1996. 143p.

CARVALHO, V.S. Morfogênese in vitro em orquídeas do grupo Cattleya. 2002. 164p. Dissertação (Mestrado), Universidade Federal de Viçosa, Viçosa.

FERREIRA, D.F. Análises estatísticas por meio do Sisvar para Windows versão 4.0. In: Reunião Anual da Região Brasileira da Sociedade Internacional de Biometria, Resumos expandidos... São Carlos: UFSCAR. p. 255-258, 2000.
JORDAN, M.I.; ROVERANO, L.; GOUREUX, A. Promotion of Annona cherimoya in vitro shoot morphogenesis as influenced by antioxidants. Gartenbauwissenschaft, Stuttgart, v. 56, n. 5, p. 224-227, 1998.

MAARTEN, W.P.C.R.; MARK, A.; LINUS, H.W.P. Role of oxidative damage in tulip bulb scale micropropagation. Plant Science, Limerick, v.130, p.207-216, 1997.

MYINT, K.T.; CHUNG, M.Y.; CHUNG, J.D.; KIN, C. Propagation via in vitro culture of leaf tissue of Phalaenopsis seedlings. Journal of Korean Society for Horticultural Science, Suwon, v. 42, n. 1, p. 1-5, 2001.

NAYAK, N.R.; SAHOO, S.; PATNAIK, S.; RATH, P.S. Establishment of thin cross section (TCS) culture method for rapid micropropagation of Ajmbidium aloifolium (L.) SW. and Dendrobium nobile Lindl. (Orquidacea) Scentia Horticulturae, Amsterdam, v.94, p.107-116, apr. 2001.

PAL, M.D.; RAYCHAUDHURI, S.S. Enhaned development of somatic embryos of Plantago ovata Forsk by additives. In Vitro Cellular and Developmental Biology Plant, Rockville, v. 37, n. 5, p. 568-571, 2001.

PARK, S.Y.; MURTHY, H.; PAEK, K.Y. Rapid propagation of Phalaenopsis from floral stalk-derived leaves. In vitro, Rockville, v.38, n.2, p.167-171, mar./abr. 2002.

PINDEL, A.; MICZYNSKIK., C. Regeneration of Cymbidium orchids from leaf and root explant. Folia Horticulturae, New York, v.8, n. 2, p. 95-105, 1996.

PIZA, I. M. T.; LIMA, G. P. P.; HENRIQUE, A.; BRASIL, O.G. Effect of $\mathrm{pH}$ on proline content and peroxidase activity in metabolism of sugarcane cultivated in vitro. Agronomia Tropical, Venezuela, v. 53, n. 2, 2003.

STIMART, D.P. Commercial micropropagation of florist flower crops. In: ZIMERMN, .H.; GRIESBACH, R.J.; HAMMERSCHLAG, F.A. (Eds). Tissue culture as a plant production system for horticultural crops. Dordrecht: Martinus Nijhoff, 1986. p. 301-316.

VENTURA, G.M.; DIAS, J.M.M.; TEIXEIRA, L.S.; CARVALHOS, S. V.; MOTOIKE, Y.S.; NOVAIS, F.R.; CECON, R.P. Organogênese in vitro a partir de gemas apicais e axilares de plantas adultas de orquídeas do grupo Cattleya. Revista Ceres, Viçosa, v. 47, n. 286 p.613-628, nov. 2002. 